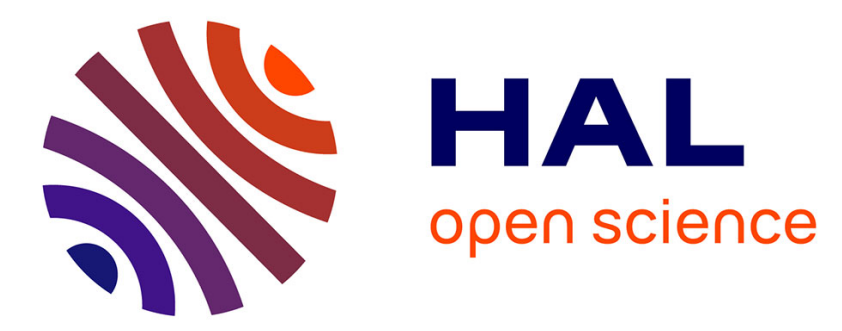

\title{
Modelling desiccation crack geometry evolution in clayey soils by analytical and numerical approaches
}

\author{
Thi Dong Vo, Amade Pouya, Sahar Hemmati, Anh Minh A.M. Tang
}

\section{To cite this version:}

Thi Dong Vo, Amade Pouya, Sahar Hemmati, Anh Minh A.M. Tang. Modelling desiccation crack geometry evolution in clayey soils by analytical and numerical approaches. Canadian Geotechnical Journal, 2019, 10.1139/cgj-2018-0105 . hal-02879232

\section{HAL Id: hal-02879232 \\ https://hal-enpc.archives-ouvertes.fr/hal-02879232}

Submitted on 23 Jun 2020

HAL is a multi-disciplinary open access archive for the deposit and dissemination of scientific research documents, whether they are published or not. The documents may come from teaching and research institutions in France or abroad, or from public or private research centers.
L'archive ouverte pluridisciplinaire HAL, est destinée au dépôt et à la diffusion de documents scientifiques de niveau recherche, publiés ou non, émanant des établissements d'enseignement et de recherche français ou étrangers, des laboratoires publics ou privés. 


\section{Modelling desiccation crack geometry evolution in clayey soils by analytical and numerical approaches}

Thi Dong Vo ${ }^{1,2}$, Amade Pouya ${ }^{1}$, Sahar Hemmati ${ }^{2}$ and Anh Minh Tang ${ }^{1}$

${ }^{1}$ Université Paris Est, Laboratoire Navier (UMR8205), Marne-la-Vallée, France

${ }^{2}$ Université Paris Est, GERS/SRO, IFSTTAR, Marne-la-Vallée, France

Corresponding author:

Dr. Anh Minh TANG

Ecole des Ponts Paris Tech

6-8 avenue Blaise Pascal, Cité Descartes, Champs sur Marne

77455 Marne-la-Vallée, Cedex 2, France

Phone: +33164153563

Email: anhminh.tang@enpc.fr 


\begin{abstract}
In the present work, the development and the geometry of desiccation cracks are studied by using a finite element code including cohesive joint elements. The numerical results show that cracking occurs sequentially to form different crack families. The propagation of each crack at the onset suddenly reaches an ultimate depth. The cracks in each family appear simultaneously and reach an identical ultimate depth. From the numerical results and additional analytical analysis, empirical correlations are proposed to predict the spacing and crack depth as a function of suction applied on the top surface, the soil parameters and the desiccation rate. The proposed model shows that higher suction is required to initiate cracks at a higher value of soil tensile strength. In addition, there is a general trend of larger spacing and deeper cracks for a slower desiccation rate. Finally, empirical relations are evaluated by comparing with in situ experimental observation published previously.
\end{abstract}

Keywords: desiccation crack, cohesive joints model, finite element method, analytical analysis, correlation. 


\section{Introduction}

The reduction of moisture content by evaporation causes soil desiccation cracking, which subsequently modifies soil mechanical and hydraulic properties. This phenomenon has therefore been intensively studied in various domains such as soil sciences, geotechnical engineering, materials sciences, etc. For instance, in geotechnical engineering, soil desiccation cracking is considered as one of the main causes inducing earth slopes instability (Baker 1981; Omidi et al. 1996; Yesiller et al. 2000). One of the key questions in these studies was the geometry of the cracks, i.e., their spacing, depth and aperture (Perrier et al. 1995).

Previous studies on desiccation cracking included generally qualitative observations of crack depth, spacing and mechanism of crack nucleation/propagation (Kodikara et al. 2002; Wang et al. 2018). These studies focused on the effect of various factors (i.e. layers thickness, drying rate, soil type, temperature, etc.) on the crack initiation and propagation (Kindle 1917; Corte and Higashi 1960; Nahlawi and Kodikara 2006; Tang et al. 2008; Peron et al. 2009; Costa et al. 2013; Sánchez et al. 2014; Stirling 2014). Some works used experimental methods to investigate the effect of these factors on crack geometry ( Corte and Higashi 1960; Lau 1987; Bai et al. 2000; Nahlawi and Kodikara 2006; Ta 2009; Song et al. 2016; Tellenaar et al. 2017). However, few works studied quantitatively the desiccation crack spacing and its relationship with crack depth.

The formation and propagation of desiccation cracks are hydro-mechanical processes. Predicting these processes by analytical or numerical approaches is very challenging. Linear Elastic Fracture Mechanics (LEFM) has been used to predict the propagation of a single crack from soil suction profile and properties (Lau 1987; Morris et al. 1991). This method was then combined with the stress relief approach to predict the crack spacing in sequential cracking (Lachenbruch 1961; Konrad and Ayad 1997a). In the stress relief approach, the spacing associated with the development of the subsequent crack depends on the stress relief induced by the previous one. As a single crack propagates to a given depth, the stress field in its vicinity is disrupted and the stress asymptotically approaches the initial 
value at a distance away. Lachenbruch (1961) and Konrad and Ayad (1997a) suggested that the subsequent crack could occur at the location where the tensile stress equals to $90-95 \%$ of the soil tensile strength. During cracking processes different crack sets are generated which are called the primary cracks, secondary and tertiary cracks (Nahlawi and Kodikara 2006; Konrad and Ayad 1997b; Amarasiri et al. 2010; Peron et al. 2009). Only the primary cracks were investigated in the works of Lachenbruch (1961) and Konrad and Ayad (1997a).

The energy balance approach, based on the energy released during the formation of a crack, was used by Peron et al. (2013) in order to predict the desiccation crack spacing. The overall energy of the system was completely released during the cracking process. The cracks were also assumed to penetrate to the whole depth of the soil specimen. This approach allowed estimating the number of blocks and thus the average crack spacing in a thin layer of soil but is not applicable to estimate the crack depth. Costa et al. (2018) used the both approaches above (stress relief and energy balance) to predict the approximate spacing-to-depth ratio of parallel cracks that form in long desiccating soil layers.

The statistical nature of the cracking process has been investigated in some studies (Chertkov and Ravina 1998; Chertkov 2008). In these studies, a physically based probabilistic model was developed, using multiple cracking and fragmentation model available for rocks, to predict the crack network geometry (opening, cross-sectional area and volume) in swelling clay soils. However, the average crack spacing and connectedness were introduced in the model as specific functions of depth.

Besides, various studies have shown that the formation of successive sets of cracks to form different families follows a dichotomy process: the subsequent cracks appear at the middle of two existing neighboring ones ( Konrad and Ayad 1997b; Nahlawi and Kodikara 2006; Amarasiri et al. 2010; Stirling 2014). The hierarchical pattern formation in desiccation cracking is investigated numerically by Hirobe and Oguni (2017). A theoretical attempt to explain this dichotomy process in the case of 
thermal cracking in asphalt pavements was presented by Timm et al. (2013) who proposed a model to predict the spacing of the successive crack families.

In the present work, the crack initiation and propagation with the formation of successive sets of cracks are firstly investigated numerically by using a finite element code including cohesive joints. The spacing and depth of each crack family are investigated. The results allow determining empirical relations for predicting crack depth and spacing. Secondly, analytical approach is used to give a deeper insight in the mechanisms of crack geometry evolution.

\section{Governing equation}

The numerical simulation was performed by using the finite element code Porofis (Pouya 2015; Vo et al. 2017) designed for coupled hydro-mechanical processes in porous fissured materials. The hydraulic flow is ignored in this study and the pore pressure profiles are directly applied. The cohesive joints elements method is included in the code to model the initiation and the propagation of desiccation cracks. The governing equations related to mechanical behavior in cracked and unsaturated porous materials are summarized as follows.

The soil matrix is assumed to be an isotropic elastic linear material. Normally, the soil modulus changes with water content and suction during drying. However, Vo et al. (2017) suggested that a constant value soil modulus would be adequate to predict the development of soil shrinkage, which is the main mechanism related to crack initiation. The relation between total stress, pore-fluid pressure and strain is expressed by the following equation:

$$
\underline{\underline{\sigma}}=C: \underline{\underline{\varepsilon}}-b p \underline{\underline{\delta}}
$$

where $\underline{\underline{\sigma}}$ is the total stress, $\boldsymbol{C}$ is the elasticity tensor, $\underline{\underline{\varepsilon}}$ is the strain tensor, $p$ is the pore-fluid pressure, $b$ is Biot coefficient and $\delta$ is the identity matrix. 
The cohesive damage crack law (Pouya and Bemani 2015) is used to describe the initiation and the propagation of cracks. The yield criterion is defined by a hyperbolic surface in the stress space, which corresponds to the following expression:

$$
F(\sigma, d)=\tau^{2}-\sigma_{n}^{2} \tan ^{2} \varphi+2 g(d) \sigma_{c} \sigma_{n}-g^{2}(d) C_{\mathrm{coh}}^{2}
$$

with : $\sigma_{c}=\frac{C_{\mathrm{coh}}^{2}+\sigma_{R}^{2} \tan ^{2} \varphi}{2 \sigma_{R}}$

where $\tau, \sigma_{n}$ are the tangential and normal stresses of the joint, $C_{\text {coh }}$ is the cohesion of the intact (undamaged) joint, $\varphi$ is the friction angle, $\sigma_{R}$ is the tensile strength of the intact joint.

The function $g(d)$ in Eq.(2) is defined such that the tensile strength $\sigma_{R}$ of the intact joint element tends to zero for a totally damaged element $g(d)=(1-d)(1-\beta \ln (1-d))$,

where $d$ is the damage variable and $\beta$ is a coefficient representing the material's ductility. The evolution of the damage variable $d$ affects both the crack stiffness and the yield surface. The cohesive damage crack behavior is represented by the following equation:

$$
\sigma_{n}=(1-d) R_{n n} u_{n}
$$

where $\sigma_{n}$ is the normal stress on the matrix/crack interface surface; $u_{n}$ is the normal component of the displacement discontinuity through the two crack's walls, $R_{n n}$ is the normal component of the joint stiffness.

The damage law in the cohesive crack model (Pouya and Bemani 2015) induces a relation between $d$ and $u_{n}$ for a monotonic traction loading given by the following relation :

$$
\begin{cases}d=0 & \text { for } u_{n}<u_{0} \\ d=1-e^{-\frac{\left(u_{n}-u_{0}\right)}{\beta u_{0}}} & \text { for } u_{n} \geq u_{0}\end{cases}
$$

with $u_{0}=\sigma_{R} / R_{n n}$ is the elastic displacement limit.

The crack aperture $(e)$ changes with the deformation from the initial value $e_{0}$ as follows $\left(e_{0}=10^{-8} \mathrm{~m}\right.$ which is negligible): 


$$
e=e_{0}+u_{n}
$$

\section{Reference case}

\section{Numerical model}

The mesh of the reference case is shown in Figure 1. That consists of a clayey soil mass having 5-m length and 1-m depth including 80 cohesive joints distributed vertically through the whole depth. The vertical displacements are prescribed in the sample bottom while all other sides are free to move. The desiccation effect is simulated by applying the suction profile (suction versus depth) directly to the soil mass. This suction decreases exponentially from the maximal value on the top surface to the deeper part. The exponential function of the suction profile is represented by two parameters: the suction on the top surface $s_{t}$ that increases with time and a constant $\gamma\left(\mathrm{m}^{-1}\right)$ that represents the suction distribution with the depth $y$. The soil suction, $s$, can be then presented by the following expression:

$$
s=s_{t} \exp (-\gamma y)
$$

Figure $2 a$ shows some examples of suction profile applied to the sample with $\gamma=15\left(\mathrm{~m}^{-1}\right)$. That represents the drying process in the soil surface. Figure $2 b$ presents the effect of $\gamma$ on the suction distribution for $s_{t}=0.05 \mathrm{MPa}$. This figure shows that the soil suction in depth is more important in the case of a smaller value of $\gamma$. Therefore, a high value of $\gamma$ presents the case of faster desiccation or a soil with a higher permeability. In the numerical simulation, $s_{t}$ is set to change with increment of $5 \times 10^{-5}$ $\mathrm{MPa}$.

As mentioned above, a set of cohesive joints is placed explicitly in the mesh to model the initiation and the propagation of potential cracks. The desiccation cracking occurs mainly with the mode I by normal opening (Towner 1987a,b; Amarasiri et al. 2011) and this mode is also assumed in the present work. Thus, the main parameters of cohesive joint are normal stiffness $\left(R_{n n}\right)$ and tensile strength $\left(\sigma_{R}\right)$. The initial parameters of cohesive joint are estimated so that their presence has no effect on the rigidity of the matrix. This means that the presence of cohesive joints does not influence the mechanical behavior of the matrix before crack initiation. Thus, the parameter $R_{n n}$ has been estimated by homogenizing the matrix mechanical properties. The tensile strength $\sigma_{R}$ is taken to be equal to the 
soil tensile strength. The parameters $C_{\mathrm{coh}}$ and $\varphi$ don't affect the mode I crack propagation which is the case in the present work. However these parameters must satisfy the inequality $C_{\text {coh }} / \tan \varphi>\sigma_{R}$ for the hyperbolic surface.

presents the parameters for the soil studied (Konrad and Ayad 1997a), for the cohesive joints and the applied suction profile used in the reference case. In this case, $\gamma$ was kept constant and the suction at the top surface $s_{t}$ was increased from 0 to $0.15 \mathrm{MPa}$ to simulate the drying process.

\section{Numerical results}

The crack depth is calculated numerically as the distance from the top surface to the last damaged joint element in which damage variable is equal to 1 . Figure 3 presents the crack depth observed at each cohesive joint versus $s_{t}$. When $s_{t}$ is smaller than $0.024 \mathrm{MPa}$, the model presents only small vertical settlement and lateral shrinkage without cracking (see also Figure 4 showing the deformed shape including the horizontal stress and the corresponding $s_{t}$ for difference steps). When $s_{t}$ exceeds 0.024 $M P a$, the first crack appears in the middle of the model (at $X=2.5 \mathrm{~m}$ ) that divides the sample into two cells. This crack can be considered as the primary crack. The subsequent increase of $s_{t}$ raises the soil tensile stress, mainly on the top surface. When $s_{t}$ reaches $0.033 \mathrm{MPa}$, two more cracks appear at $X=$ $1.25 \mathrm{~m}$ and $3.75 \mathrm{~m}$, exactly in the middle between the primary crack and the extreme boundaries of the sample. This scenario is repeated at $s_{t}=0.051 \mathrm{MPa}$ and at $s_{t}=0.0975 \mathrm{MPa}$ to initiate the $3^{\text {rd }}$ and the $4^{\text {th }}$ crack families following the dichotomy process (the subsequent cracks are created in the middle of two neighboring existing cracks). In addition, it can be seen that the cracking occurs sequentially to form different crack families. However, the cracks initiate simultaneously at the same value of suction for each family. In Figure 3, the depth evolution of cracks shows also two phases. In the first phase, cracks initiate suddenly to reach ultimate depths (instable propagation) and then in the second phase, cracks propagate more slowly with the increasing of suction $s_{t}$ (stable propagation). The ultimate crack depths for each family are similar. Additionally, this ultimate depth is higher for the cracks that appear earlier. The existence of an unstable or instantaneous crack propagation has been already observed by Sanchez et al. (2013) in laboratory tests where crack reached the ultimate depth in a short time. The 
sudden crack propagation is explained in fracture mechanics by energy cumulated during the shrinkage inside the soil mass before crack initiation (Konrad and Ayad 1997a).

As mentioned above, there are 80 cohesive joints placed in the model, but there are only 15 opened cracks when $s_{t}$ reaches $0.15 \mathrm{MPa}$. Further drying would create more cracks but the results would be influenced by the mesh refinement (the number of cohesive joints between the two existing crack should be adequately high to have a good prediction). The spacing between the cracks is considered as the distance between two neighboring opened cracks. From Figure 4, the spacing can be evaluated for different steps of desiccation. If the spacing between cracks is designated as $D$, the crack density is thus considered as $1 / D$. On Figure 5, the crack density is plotted versus $s_{t}$ (the continuous line). The points on this curve represent the initiation of each crack family. These points are then fitted with a linear function that is represented by the discontinuous line. Besides, these results indicate that the crack density remains constant in some range of suction. The change of suction to initiate a new crack family is more important at a higher crack density.

The average ultimate depths $(L)$ for different crack families are plotted versus the crack spacing in Figure $6 a$. Note that $L$ corresponds to the average crack length obtained after onset of cracking (see Figure 3); the increase of crack depth with increasing of suction is not considered. As mentioned above, larger crack spacing corresponds to a higher ultimate crack depth. In Figure $6 b$, the crack depth is plotted versus the square root of crack spacing that allows showing a good linear correlation between these two parameters.

In order to better understand the crack geometry evolution, in Figure 7, the tensile stress on the top surface of the sample is plotted for different steps corresponding to the initiation of new crack families. When $s_{t}=0.024 \mathrm{MPa}$, the tensile stresses are minimal near the two lateral boundaries while the maximal tensile stress approaches the tensile strength $\sigma_{R}(0.0085 \mathrm{MPa})$ in the middle of the sample. The primary crack in the middle $(X=2.5 \mathrm{~m})$ is then initiated with a small increase of suction (at $s_{t}=0.0255 \mathrm{MPa}$ ) because the stress criterion is reached. The apparition of this primary crack causes the stress decrease in the crack location and also in the vicinity of this crack (the path number 1). For the zone far from this crack (i.e. two zones beside the lateral boundaries), the tensile stress 
remains quasi identical before and after the formation the first crack. The tensile stress reduces to zero on the crack line. This latter divides the sample into two parts and the maximum tensile stresses are observed at the middle of each part. When $s_{t}$ increases up to $0.0315 \mathrm{MPa}$ (the path number 2), the tensile stresses in the middle of the two parts approaches again the tensile strength $\sigma_{R}(0.0085 \mathrm{MPa})$. With $s_{t}=0.033 \mathrm{MPa}$, the secondary cracks (at $X=1.25 \mathrm{~m}$ and $3.75 \mathrm{~m}$ ) are initiated according to the stress criterion. The tensile stresses are then decreased after the apparition of these cracks (the path number 3) and the process is repeated during desiccation. The initiation of tertiary and quaternary cracks can then be explained in the same manner.

\section{Parametric study}

Figure 8 shows the crack density evolution during desiccation with different values of $\gamma$; the other parameters are identical to those shown in Table 1. As the reference case, the points representing crack initiation can be fitted by a linear function for each case. The results show that, for the same crack density, the cracking occurs at a higher suction for a smaller $\gamma$. Interestingly, the first crack appears at a suction of about $0.02 \mathrm{MPa}$ for all values of $\gamma$.

The average ultimate crack depth $(L)$ for each crack family is plotted versus its square root of spacing for different values of $\gamma$ in Figure 9. The correlation between crack depth and the square root of spacing can be equally fitted by linear functions for all values of $\gamma$. The results show that, for the same crack spacing, the ultimate depth is higher for a lower $\gamma$.

To investigate the effect of $\sigma_{R}$ on the relationship between crack density and $s_{t}$, simulations have been done with various values of $\sigma_{R}\left(\gamma\right.$ equals to $15 \mathrm{~m}^{-1}$ and the others parameters are identical to those shown in Table 1). The obtained results are shown in Figure 10. These results evidence that higher $s_{t}$ is required to reach the same crack density with a higher $\sigma_{R}$. Actually, cracking occurs when the tensile stress reaches the tensile strength. Higher tensile strength requires higher tensile stress, and this latter is closely related to $s_{t}$.

\section{Empirical correlation and analytical analysis}

\section{Empirical correlation for crack density}


From the results shown in Figure 8 and Figure 10, the following empirical correlation can be proposed to predict the crack density:

$$
\frac{1}{D}=k(\gamma)\left(\frac{s-s_{0}}{\sigma_{R}}\right)
$$

where:

- $s_{0}$ is the suction initiating the first crack in the case where the length of the soil mass is infinitely long. In the present work, as the soil mass has a length of $5 \mathrm{~m}$, the first crack corresponds already to $1 / \mathrm{D}=0.4\left(\mathrm{~m}^{-1}\right)$.

- $\quad k(\gamma)$ is a parameter depending on the desiccation rate (function of $\gamma$ )

From the Eq.(7), the crack spacing can be determined as follows:

$$
D=\frac{1}{k(\gamma)}\left(\frac{\sigma_{R}}{s-s_{0}}\right)
$$

From Figure 8, $s_{0}$ can be determined by extrapolating these curves to the horizontal axis $x$. Besides, this suction can be determined from the analysis of stress field in the soil surface before cracking by considering the soil behavior as elastic and isotropic. Actually, before cracking, the following total stress field in the sample can be determined from the boundary conditions and the momentum equations (Vo 2017):

$$
\left\{\begin{array}{l}
\sigma_{x x}=\frac{-2 \mu}{(\lambda+2 \mu)} b p(y) \\
\sigma_{y y}=0
\end{array}\right.
$$

where $\lambda, \mu$ are the Lamé coefficients of soil which can be determined from the elastic modulus $E$ and Poisson ratio $v$.

Cracking occurs when the tensile stress reaches the tensile strength $\sigma_{R}$. Under evaporation, soil suction is maximal on the top surface and the cracks are always initiated from this surface. The suction $s_{0}$ on this surface ( $y=0$ in the Eq. (9)) is determined as follows: 


$$
\sigma_{x x}(y=0)=\frac{-2 \mu}{(\lambda+2 \mu)} b p(y=0)=\frac{-2 \mu}{(\lambda+2 \mu)} b s_{0}=\sigma_{R}
$$

By replacing $\frac{\lambda}{\mu}=\frac{2 v}{1-2 v}$ in Eq. (10), the $s_{0}$ can be then determined:

$$
s_{0}=\sigma_{R} \frac{1}{b}\left(\frac{1-v}{1-2 v}\right)
$$

Eq. (11) indicates that a higher tensile strength $\sigma_{R}$ leads to a higher crack initiation value $s_{0}$. It is in agreement with the trend of the curves presented in Figure 10. Besides, Eq. (11) shows that $s_{0}$ is independent of $\gamma$, which seems to be in agreement with the results shown in Figure 8. By replacing $b=$ 1 and $v=0.3$ (usually used in soil mechanics), $s_{0}$ can be analytically estimated from $\sigma_{R}$ by using Eq. (11). Figure 11 shows $s_{0}$ versus $\sigma_{R}$ for both empirical correlation and analytical methods. It is interesting to note that these two independent methods, the empirical correlation one by extrapolation of the results shown in Figure 8 and Figure 10 and the analytical one by using Eq. (11), give similar values for $s_{0}$. Actually, the analytical method corresponds to the case where the length of the soil mass is infinitely high. Which is also in agreement with the definition of $s_{0}$ in the empirical correlation method (equation 7).

Besides, from field observation, Konrad and Ayad (1997b) showed that the suction at the surface was about $0.02 \mathrm{MPa}$ at the initiation of cracks for soil having tensile strength equals $0.01 \mathrm{MPa}$. By replacing $\sigma_{R}=0.01 \mathrm{MPa}$ in Eq. (11), the suction $s_{0}$ can be analytically estimated at $0.018 \mathrm{MPa}$. This value is very close to the value measured by Konrad and Ayad (1997b). A good agreement between the three methods (analytical, numerical and experimental) in the calculation of $s_{0}$ allows validating the assumptions used in the empiric correlation.

In Eq. (7), $k(\gamma)$ is a function representing the effect of the drying rate on crack density and spacing. From the results shown in Figure 8 the value of $k$ corresponding to each value of $\gamma$ is plotted (see Figure 12). From this figure, $k(\gamma)$ can be determined approximately by the following equation:

$$
k=4 \gamma
$$

By replacing Eq. (12) in Eq. (7), the crack density can be estimated: 


$$
\frac{1}{D}=4 \gamma\left(\frac{s-s_{0}}{\sigma_{R}}\right)
$$

Then, the crack spacing can be deducted from the empirical correlation in Eq. (13) as follows:

$$
D=\frac{1}{4 \gamma}\left(\frac{\sigma_{R}}{s-s_{0}}\right)
$$

\section{Empirical correlation for crack depth}

Figure 9 indicates that for each value of $\gamma$, a linear function can express with a good precision the correlation between the crack ultimate depth and the square root of crack spacing. This correlation also depends on $\gamma$. The following empirical correlation can be proposed to estimate the ultimate depth $L$ according to the numerical results presented in Figure 9:

$$
L=f(\gamma) \sqrt{D}
$$

where $f(\gamma)$ is a function representing the effect of desiccation rate on the cracking geometry. From the results shown in the Figure 9, the value of $f$ for each case of $\gamma$ was determined and plotted in the Figure 13. $f(\gamma)$ can be then estimated from $\gamma$ by the following equation:

$$
f=0.507 \sqrt{\frac{1}{\gamma}}+0.0403
$$

By replacing Eq.(16) in Eq. (15), the crack ultimate depth can be estimated as follows:

$$
L=\left(0.507 \sqrt{\frac{1}{\gamma}}+0.0403\right) \sqrt{D}
$$

Eq. (17) allows estimating the ultimate depth of crack by knowing the spacing $D$ between cracks and the suction distribution through the constant $\gamma$. In addition, if the crack spacing can be calculated approximately from Eq. (14), the crack depth can also be calculated as a function of suction, tensile strength and desiccation rate. The proposed correlation in Eq. (17) indicates that with the same $\gamma$, a smaller $D$ corresponds to a smaller $L$. This means that the ultimate depth decreases from the primary to secondary and tertiary cracks when the spacing decreases (Figure 3). In addition, when a crack family is considered (with a same spacing $D$ ), a lower drying rate $\gamma$ gives a higher ultimate depth. 
Konrad and Ayad (1997b) investigated the desiccation of a sensitive clay by field experimental observation. An excavation with three different levels was exposed to continuous evaporation during 35 days in order to observe the formation of desiccation cracks. Desiccation of the intact Saint- Alban clay ( $2 \mathrm{~m}$ below the top surface) under restrained conditions, at an average evaporation rate of 0.18 $\mathrm{mm} / \mathrm{h}$ produced visible primary cracks after $17 \mathrm{~h}$ with an average spacing of $0.20-0.24 \mathrm{~m}$ and a depth of $0.05-0.07 \mathrm{~m}$ at the onset. Close to crack initiation, the suction on the surface was measured at about $20 \mathrm{kPa}$. These field data of intact clay were also used by Ayad et al. (1997) to evaluate the performance of the model CRACK enabling the prediction of depth and spacing of primary desiccation cracks (Konrad and Ayad 1997a). The ultimate depth crack was determined by the LEFM approach while the spacing was proposed by using the stress relief approach. For this field study, model suggested that the ultimate crack depth ranged from 0.08 to $0.11 \mathrm{~m}$. In addition, from an opened crack, another crack can initiate when the total horizontal stress reaches about $80-88 \%$ of the tensile strength value. Other researchers (Lachenbruch 1961; Kodikara and Choi 2006) have also noted that secondary cracks appear at a tensile stress 5\%-10\% less than the tensile strength. Note that in the present work, the secondary cracks appear at a tensile stress equal to the tensile strength (Figure 7). Actually, in the present work, because of the dichotomy process, the subsequent cracks are created in the middle of the two neighboring existing cracks, when the yield criterion is reached for the secondary cracks, the tangential stress of the joint equals zero. For this reason, the yield criterion is reached with the normal stress (tensile stress) equal to the tensile strength. For these other cases where the tangential stress exists, crack appear when the tensile stress is lower than the tensile strength (see equation 2).

From Eq. (17), the coefficient $\gamma$ can be determined as a function of depth $(L)$ and spacing $(D)$. In the study of Konrad and Ayad (1997b), $L=0.05-0.07 \mathrm{~m}$ and $D=0.20-0.24$ for primary cracks. As a result, $\gamma=5 \times 10^{-4}-2 \times 10^{-3} \mathrm{~m}^{-1}$. These values of $\gamma$ and the suction on the surface at crack initiation can be introduced in Eq. (6) to determine the suction profile. 
Figure 14 shows the suction profiles at the crack initiation obtained by various methods: (i) field measurement provided by Konrad and Ayad (1997b) using tensiometers; (ii) estimation from moisture content data by Konrad and Ayad (1997b) (iii) theoretical profile calculated by Ayad et al. (1997) using the fictitious stress superposition concept; (iv) Eq. (6) with $\gamma=5 \times 10^{-4}-2 \times 10^{-3} \mathrm{~m}^{-1}$. It can be seen that the proposed model can fit very well the experimental data with $\gamma=5 \times 10^{-4}$ or $6 \times 10^{-4} \mathrm{~m}^{-1}$ and very close to the predicted model proposed by Ayad et al. (1997) with $\gamma=1 \times 10^{-3} \mathrm{~m}^{-1}$. The good agreement between the field data and the proposed model allows validating the empirical correlation obtained from the numerical results in the present work.

\section{Discussions}

In the present work, the desiccation is simulated by applying a soil suction profile that varies in time. Actually, the suction distribution in depth results from the hydraulic diffusion and it can be influenced by soil properties (e.g. permeability and the desiccation rate). In some studies on desiccation cracking, a linear profile of suction were suggested (Lau 1987; Morris et al. 1991). However, this condition is rarely reached in practice and it is more common to observe a nonlinear distribution of suction in depth (Morris et al. 1991; Konrad and Ayad 1997b; Stirling 2014). An exponential suction profile was used in the present work based on previous studies. These suction profiles are represented by two parameters: the suction on the surface $s_{t}$ and the constant $\gamma$. The suction $s_{t}$ increases during the desiccation while the constant $\gamma$ represents indirectly the desiccation rate: a high value of $\gamma$ corresponds to a higher desiccation rate. The agreement between the suction profiles calculated by the proposed model; the field data (Konrad and Ayad 1997b) and the model of Ayad et al. (1997) shown in the Figure 14 validates the choice of suction profile in the present work.

Numerical simulation results (Figure 4) show that cracking occurs sequentially to form primary, secondary and tertiary cracks. In addition, for each crack family, the cracks appear simultaneously with an identical ultimate depth at the same suction level. The experimental observations performed by Peron et al. (2013) indicated a combination of two processes, "sequential infilling" or "simultaneous growing" in desiccation cracking since the cracks tend to appear either successively or 
simultaneously. The numerical results in Figure 4 present the process of breaking the intact soil into individual blocks to form different crack families. This breaking scenario was also found in numerical studies (Amarasiri et al. 2010; Stirling 2014; Sánchez et al. 2014), laboratory experiments (Nahlawi and Kodikara 2006) and in situ observation (Konrad and Ayad 1997b). The formation of successive sets of cracks follows a dichotomy process: the new set of cracks appears at the middle location of two neighboring exist cracks. This phenomenon is explained by tensile stress evolution shown in Figure 7 . In addition, there are two major factors which control the crack initiation: stress distribution and flaw presence (Kodikara and Costa 2013). Based on the stress distribution, the cracks initiate always at the midpoint of soil mass without flaws (free sides) where the stress is probably maximal (Kodikara and Choi 2006; Peron et al. 2013; Kodikara and Costa 2013). The dichotomy process was assumed in the study on thermally-induced cracking (Timm et al. 2003; Leguillon et al. 2017). Timm et al. (2003), by studying thermally-induced cracking in pavement, explained that in the absence of material flaws, symmetry considerations suggest that the crack form at the midpoint, dividing the undamaged section into equal parts. With subsequent cooling, the cracking and subdividing of pavement section continue. Figure 5 shows that the crack density (crack spacing) remains constant in some ranges of suction in which the tensile stress between cracks recovers, reaches the strength and forms the subsequent cracks. The influence of suction evolution on the crack density (or crack spacing) is then taken into account in Eq.(7).

Crack initiation is generally predicted using strength criterion. Following the numerical results presented in Figure 3, the propagation of cracks at the initiation moment occurs suddenly to reach an ultimate depth. In fact, once crack is initiated, the propagation depth is governed by energy criterion: the elastic energy released by cracking is equal to the energy needed for the formation of the crack surface which is characterized by material's fracture toughness (Leguillon 2002; Leguillon et al. 2016). The ultimate depth of an isolated crack was also predicted by LEFM (Lachenbruch 1961; Konrad and Ayad 1997a). The crack ultimate depth is likely identical for each family and decreases from the primary to the secondary and tertiary cracks (Figure 3 and Figure 9). 
The present work proposes empirical relations to predict the spacing and depth at the onset of desiccation cracks. These relations are essentially based on the numerical results and some theoretical analysis. The spacing between cracks was predicted in some research ( Lachenbruch 1961; Konrad and Ayad 1997a; Peron et al. 2013) for primary cracks. These researches have also shown that the spacing can be qualitatively affected by the soil layer thickness, the desiccation rate, soil properties, water content, drying/wetting cycle ( Kindle 1917; Nahlawi and Kodikara 2006; Peron et al. 2009; Stirling 2014; Sánchez et al. 2014;). In the present work, the thickness of soil mass is relatively high (compared to the depth of the zone affected by suction changes). For this reason, the results are independent of soil layer thickness. From the empirical correlation proposed in Eq.(7), crack spacing can be easily calculated from the actual suction on the surface $s_{t}$, the tensile strength $\sigma_{R}$, Poisson ratio $v$ and the desiccation rate represented by $\gamma$. In this relation, $s_{0}$ is the minimal suction on the surface from which cracks occur. This suction can be calculated analytically from stress field of soil surface before cracking. The good agreement of the values of $s_{0}$ for different values of $\sigma_{R}$ calculated by analytical and the proposed model is presented in Figure 11. In addition, the proposed model (Eq. (14) and Eq. (17)) shows that the increase of tensile strength can influence to the spacing and crack depth. Besides, a larger spacing and deeper desiccation cracks can be obtained under a slow desiccation (smaller $\gamma$ ). These observations are in agreement with some other studies (Kindle 1917; Corte and Higashi 1960; Morris et al. 1991; Konrad and Ayad 1997b; Ayad et al. 1997; Costa et al. 2013; Stirling 2014).

In this paper, the initiation and propagation of desiccation cracks are investigated using the cohesive joints elements method. In the simulations, the hydraulic flow is neglected and the desiccation is simulated by directly applying the suction profile. In addition, the soil behavior is assumed linear elasticity. Despite these assumptions, the paper allows assessing the simultaneous crack initiation and the crack propagation. Crack geometry can be also predicted by the present method. In future works, the non-linearity of soil behavior in desiccation and the application can be considered. In additions, the proposed model can be applied to real-scale earthen structures. 


\section{Conclusions}

The present work focuses on the initiation and the propagation of desiccation cracks by using a FEM code including cohesive joint elements. A suction profile, which varies in time, is imposed to simulate the hydraulic flow. The numerical results show that cracking occurs sequentially to form different crack families. Cracks appear simultaneously at the same suction level for each family. Geometrically, the formation of successive sets of cracks follows a dichotomy process: the subsequent set of cracks appears at the middle location of two neighboring existing cracks. The numerical simulation indicates also two main phases in the crack propagation: (i) sudden to reach an ultimate depth at the onset moment; (ii) and progressive once the crack is opened. The cracks in each family present the same ultimate depth, which decreases from the primary cracks to the subsequent families.

Based on the numerical results, empirical correlations have been proposed to estimate crack spacing and depth from soil parameters (tensile strength, Poisson ratio, Biot coefficient), the desiccation rate (parameter $\gamma$ ) and the suction on the top surface $\left(s_{t}\right)$. These correlations show that a higher suction is required to initiate crack in soil with a higher tensile strength. In addition, there is a general trend of larger spacing and deeper cracks for a slower desiccation. 
Acknowledgement

The authors would like to thank Professor Dominique Leguillon for his fruitful discussion and contributions to the ideas presented in this paper. 


\section{REFERENCES}

Amarasiri, A., Kodikara, J. and Costa, S. 2010. Numerical modelling of desiccation cracking. International Journal for Numerical and Analytical Methods in Geomechanics, 35: 82-96.

Amarasiri, A.L., Costa, S. and Kodikara, J.K. 2011. Determination of cohesive properties for mode I fracture from compacted clay beams. Canadian Geotechnical Journal, 38: 1163-1173.

Ayad, R., Konrad, J.-M. and Soulié,M. 1997. Desiccation of a sensitive clay: application of the model CRACK. Canadian Geotechnical Journal, 34: 943-951.

Bai, T., Pollard, D.D. and Gao, H. 2000. Explanation for fracture spacing. Nature, 403: 753-756.

Baker, R. 1981. Tensile strength, tension cracks, and stability of slopes. Soils and Foundations, 21: 117.

Chertkov, V.Y. 2008. The Geometry of Soil Crack Networks. The open Hydrology Journal, 2: 34-48.

Chertkov, V.Y. and Ravina, I. 1998. Modeling the crack network of swelling clay soils. Soil Science Society of America Journal, 62: 1162-1171.

Corte, A. and Higashi, A. 1960. Experimental Research on Desiccation Cracks in Soil. Research Report, Army Snow Ice and Permafrost Research Establishment, USA.

Costa, S., Kodikara, J. and Shannon, B. 2013. Salient factors controlling desiccation cracking of clay in laboratory experiments. Géotechnique, 63: 18-29.

Costa, S., Kodikara, J., Barbour, S.L. and Fredlund, D.G. 2018. Theoretical analysis of desiccation crack spacing of a thin, long soil layer. Acta Geotechnica, 13(1): 39-49.

Hirobe, S. and Oguni, K. 2017. Modeling and numerical investigations for hierarchical pattern formation in desiccation cracking. Physica D, 359: 29-38.

Kindle, E. 1917. Some factor affecting the development of mud-cracks. Chicago Journals, 25: 135144.

Kodikara, J., Barbour, S.L. and Fredlund, D.G. 2002. Structure development in surficial heavy clay soils: a synthesis of mechanisms. Australian Geomechanics, June: 25-40. 
Kodikara, J. and Costa, S. 2013. Desiccation Cracking in Clayey Soils: Mechanisms and Modelling. Multiphysical Testing of Soils and Shales, 21-32.

Kodikara, J.K. and Choi, X. 2006. A simplified analytical model for desiccation cracking of clay layers in laboratory tests. Fourth International Conference on Unsaturated Soils. ASCE Geotechnical Special Publication, 2: 2558- 2567.

Konrad, J.-M. and Ayad, R. 1997a. An idealized framework for the analysis of cohesive soils undergoing desiccation. Canadian Geotechnical Journal, 34: 477-488.

Konrad, J.-M. and Ayad, R. 1997b. Desiccation of a sensitive clay: field experimental observations. Canadian Geotechnical Journal, 34: .929-942.

Lachenbruch, A.. 1961. Depth and spacing of tension cracks. Journal of Geophysical Research, 66: 4273-4292.

Lau, J.T. 1987. Desiccation cracking of soils. Thesis Report. University of Saskatchewan, 286 pages.

Leguillon, D., Lafarie-Frenot, M.C., Pannier, Y. and Martin, E. 2016. Prediction of the surface cracking pattern of an oxidized polymer induced by residual and bending stresses. International Journal of Solids and Structures, 91: 89-101.

Leguillon, D. 2002. Strength or toughness ? A criterion for crack onset at a notch. European Journal of Mechanics A/Solids, 21: 61-72.

Leguillon, D., Li, J. and Martin, E. 2017. Multi-cracking in brittle thin layers and coatings using a FFM model. European Journal of Mechanics / A Solids, 63: 14-21.

Morris, P.H., Graham, J. and Williams, D.J. 1991. Cracking in drying soil. Can.Geotech, 29: 263-277.

Nahlawi, H. and Kodikara, J.K. 2006. Laboratory experiments on desiccation cracking of thin soil layers. Geotechnical and Geological Engineering, 24: 1641-1664.

Omidi, G.H., Thomas, J.C. and Brown, K.W. 1996. Effect of desiccation cracking on the hydraulic conductivity of a compacted clay liner. Water, Air, and Soil Pollution, 89: 91-103.

Peron, H., Hueckel, T., Laloui, L. and Hu, L.B. 2009. Fundamentals of desiccation cracking of fine- 
grained soils : experimental characterisation and mechanisms identification. Canadian Geotechnical Journal, 46: 1177-1201.

Peron, H., Laloui, L., Hu, L.B. and Hueckel, T. 2013. Formation of drying crack patterns in soils: A deterministic approach. Acta Geotechnica, 8: 215-221.

Perrier, E., Mullon, C. and Rieu, M. 1995. Computer construction of fractal soil structures: Simulation of their hydraulic and shrinkage properties. Water Resources Research, 31: 2927-2943.

Pouya, A. 2015. A finite element method for modeling coupled flow and deformation in porous fractured media. International Journal for Numerical and Analytical Methods in Geomechanics, 39: $1836-1852$

Pouya, A. and Bemani, P. 2015. A damage-plasticity model for cohesive fractures. International Journal of Rock Mechanics and Mining Sciences, 73: 194-202.

Sánchez, M., Manzoli, O.L. and Guimarães, L.J.N. 2014. Modeling 3-D desiccation soil crack networks using a mesh fragmentation technique. Computers and Geotechnics, 62: 27-39.

Song, W-K., Cui, Y-J., Tang, A-M., Ding, W-Q. and Wang, Q. 2016. Experimental study on water evaporation from compacted clay using environmental chamber. Can.Geotech, 53: 1293-1304

Stirling, R.A. 2014. Multiphase Modelling of Desiccation Cracking in Compacted Soil. Thesis Report. Newcastle University, 363 pages.

Ta, A.N. 2009. Etude de l'interaction sol- atmosphère en chambre environnementale. Thesis Report. Ecole Nationale des Ponts et Chaussées, 203 pages

Tang, C., Shi, B., Liu, C., Zhao, L. and Wang, B. 2008. Influencing factors of geometrical structure of surface shrinkage cracks in clayey soils. Engineering Geology, 101: 204-217.

Timm, D.H., Guzina, B.B. and Voller, V.R. 2003. Prediction of thermal crack spacing. International Journal of Solids and Structures, 40: 125-142.

Towner, 1987a. The Mechanics of Cracking of Drying. Journal of Agricultural Engineering Research, 36: $115-124$. 
Towner, 1987b. The Tensile Stress Generated in Clay through Drying. Journal of Agricultural Engineering Research, 37: 279-289.

Vo, T.D., Pouya, A., Hemmati, S. and Tang, A-M. 2017. Numerical modelling of desiccation cracking of clayey soil using a cohesive fracture method. Computers and Geotechnics, 85: 15-27.

Vo, T.D. 2017. Modélisation numérique et analytique de la fissuration de séchage des sols argileux. Thesis Report. Universite Paris-Est, 210 pages.

Wang, L.L, Tang, C-S., Shi, B., Cui, Y-J., Zhang, G.Q., and Hilary, I. 2018. Nucleation and propagation mechanisms of soil desiccation cracks. Engineering Geology, 238: 27-35

Yesiller, N., Miller, C. J., Inci, G. and Yaldo, K. 2000. Desiccation and cracking behavior of three compacted landfill liner soils. Engineering Geology, 57: 105-121. 
Figure 1: Geometry and boundary conditions of reference case

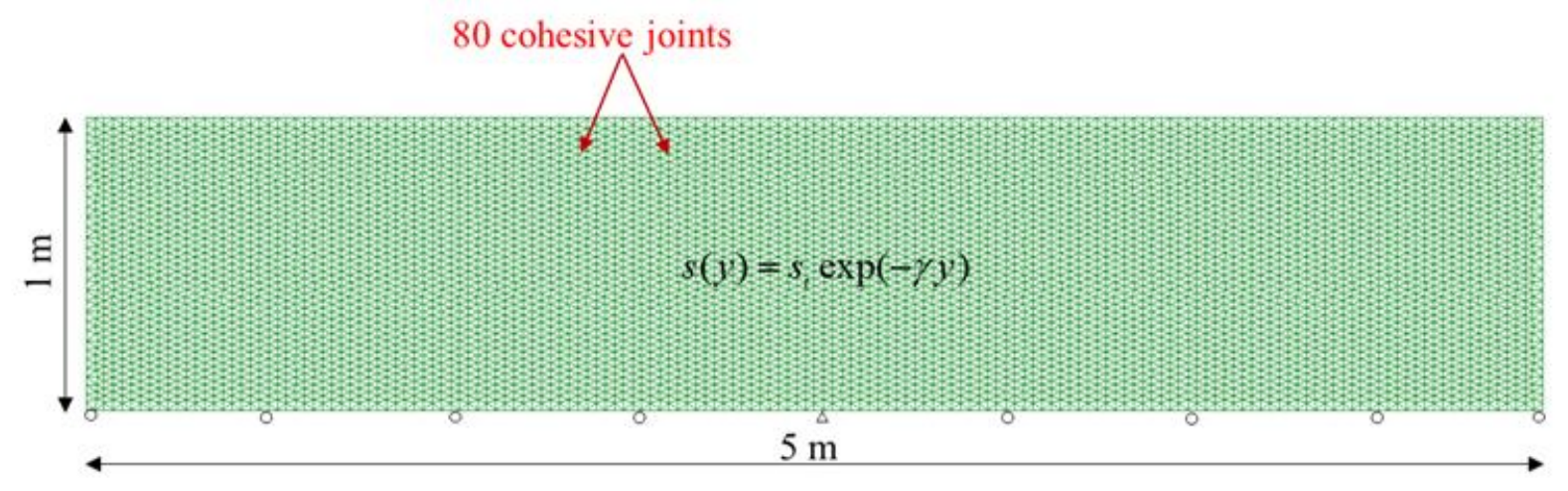

Figure 2: Examples of suction profile: (a) with different suctions on the surface and (b) with different values of $\gamma$ 


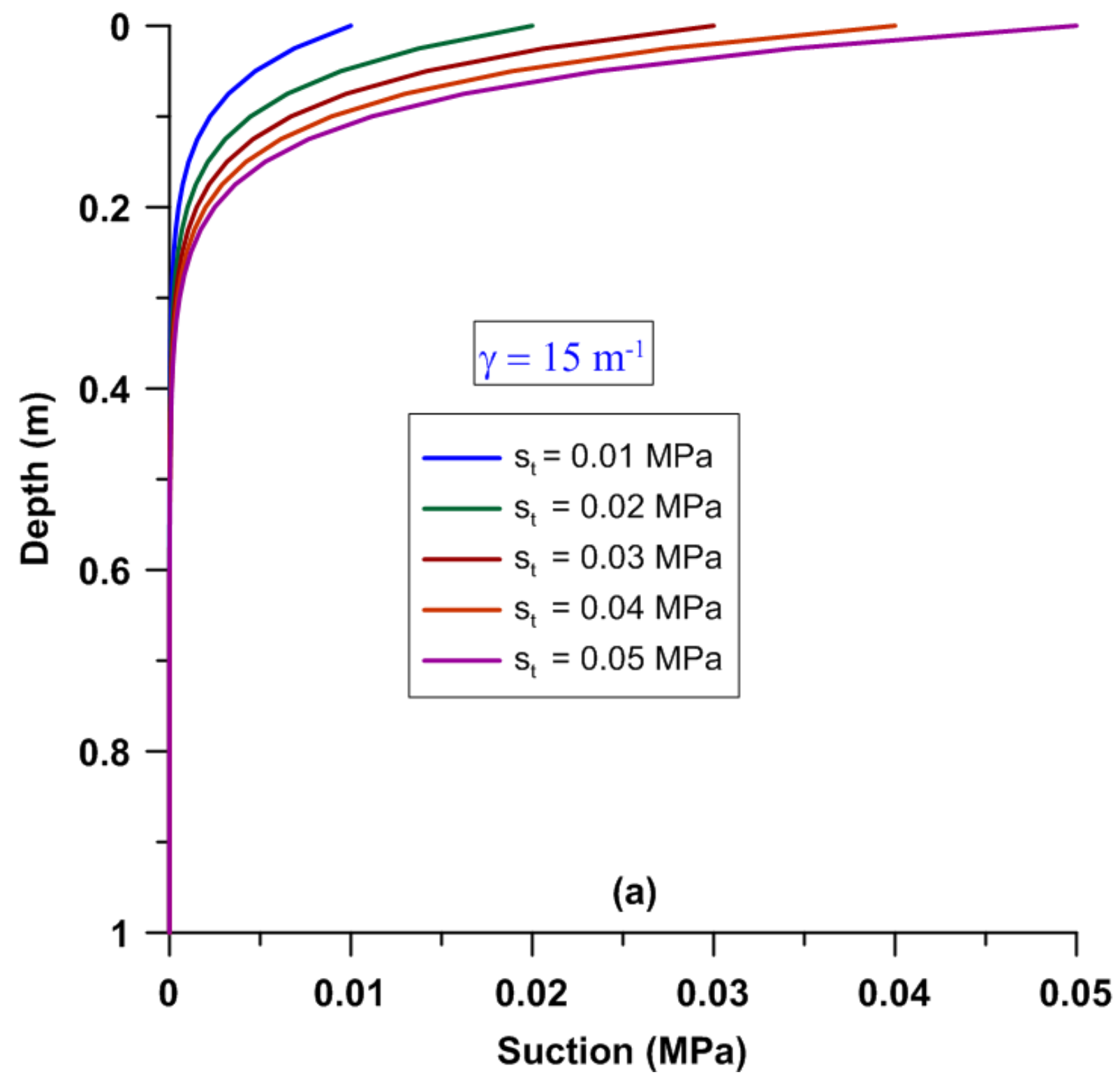




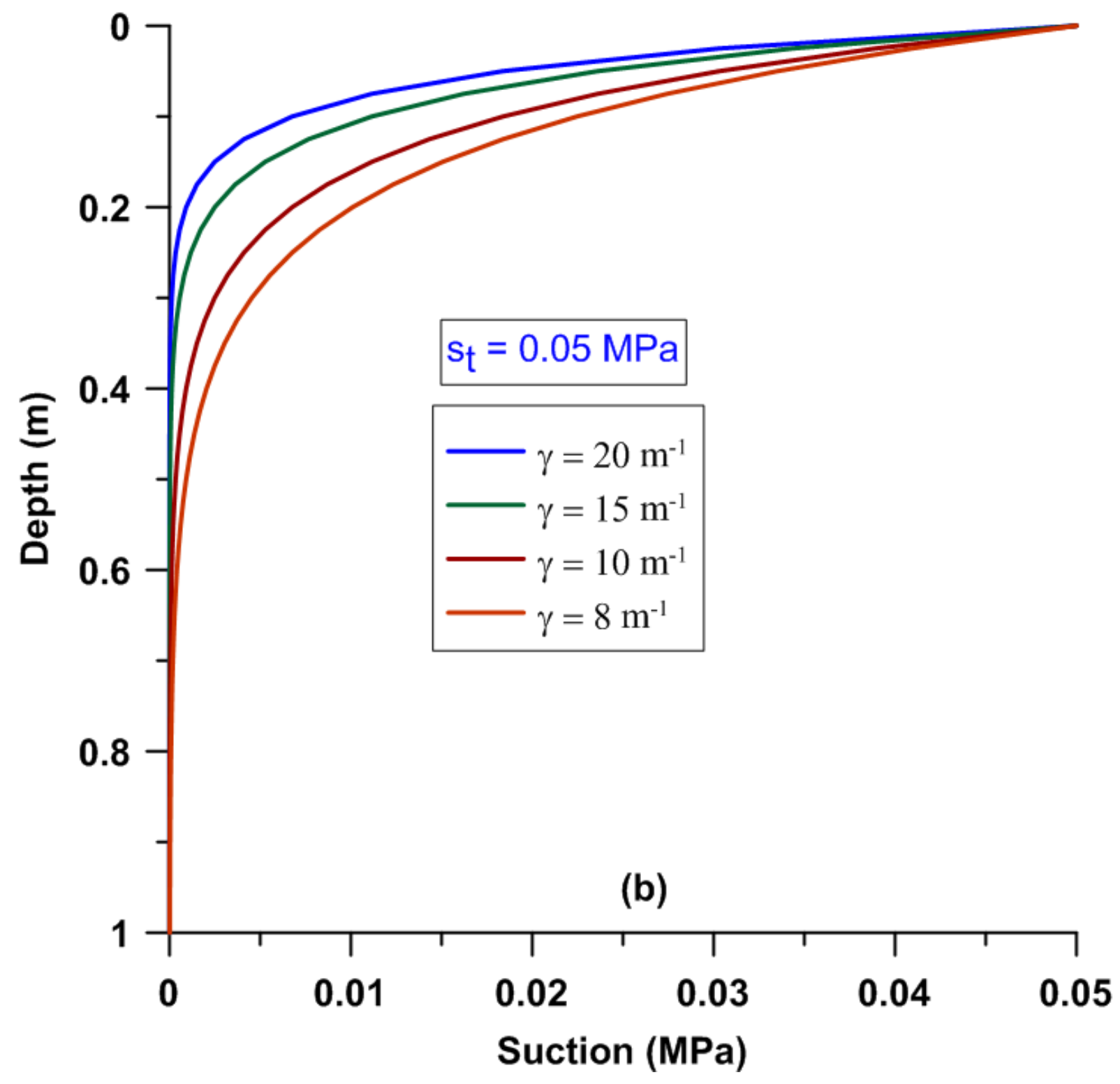

Figure 3: Crack depth versus suction on the top surface 


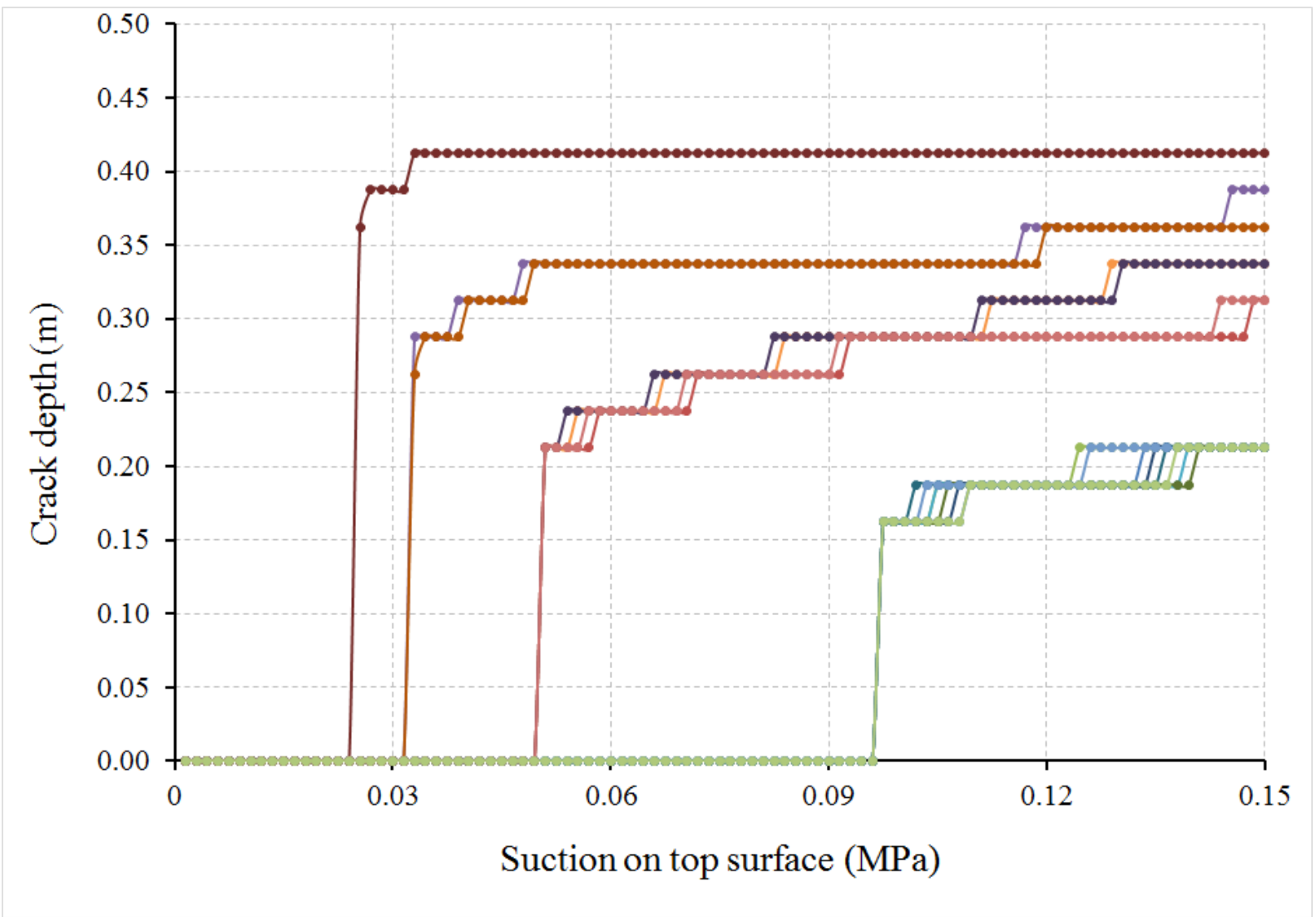

Figure 4: Crack development with the suction evolution on the top surface 
$s_{t}=0 \mathrm{MPa}$

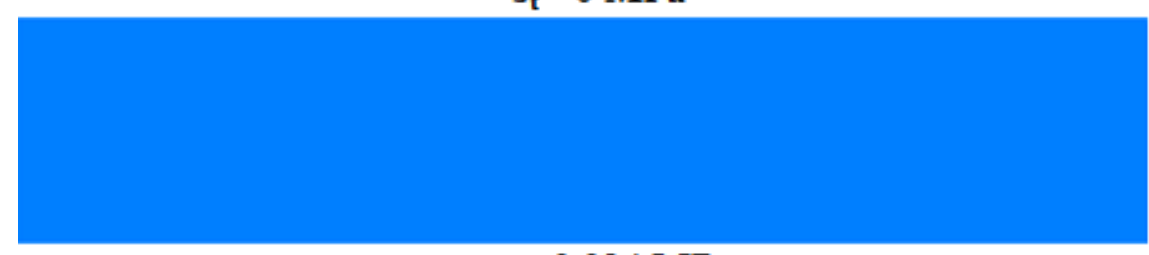

$s_{t}=0.024 \mathrm{MPa}$

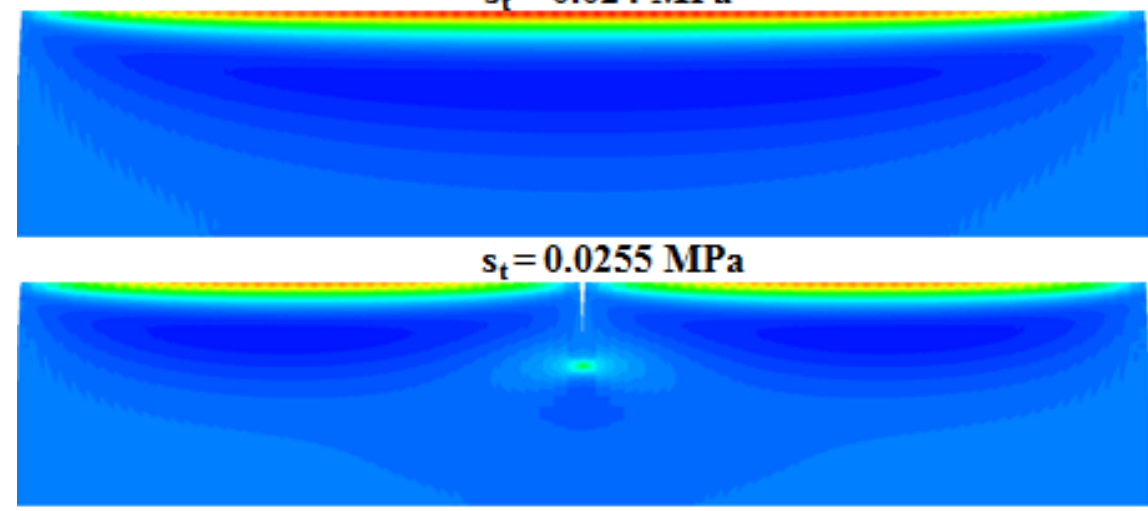

Sxx

$s_{t}=0.033 \mathrm{MPa}$

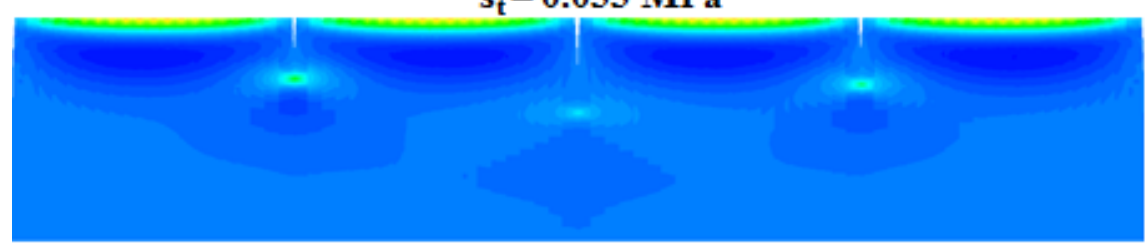

$s_{t}=0.051 \mathrm{MPa}$

\begin{tabular}{l}
\hline$\overline{0.01072}$ \\
0.0091814 \\
0.0076425 \\
0.0061035 \\
0.0045645 \\
0.0030255 \\
0.0014866 \\
$-5.239 e-05$ \\
-0.0015914 \\
-0.0031303 \\
\hline
\end{tabular}

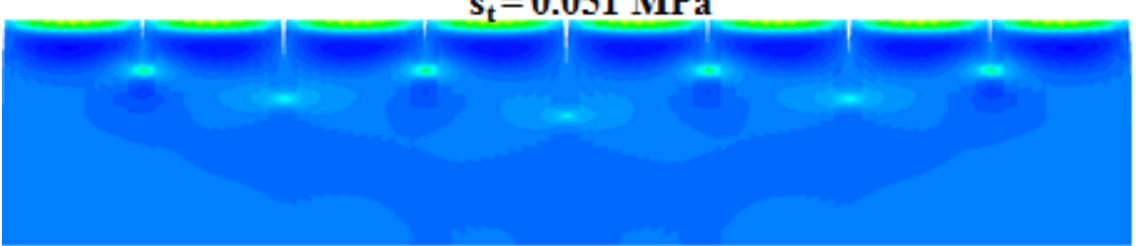

$s_{t}=0.0975 \mathrm{MPa}$

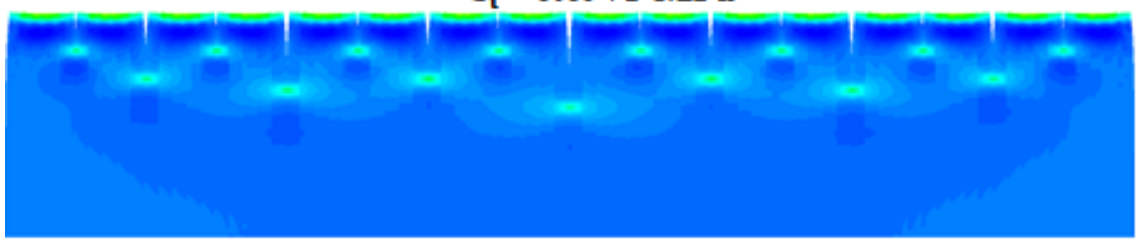

$s_{t}=0.15 \mathrm{MPa}$

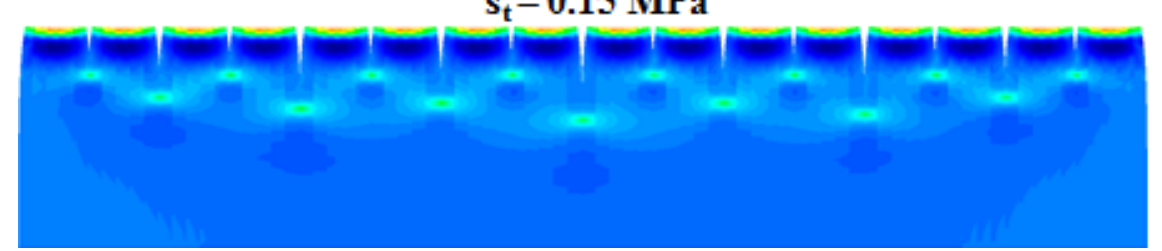


Figure 5: Cracks density versus suction on the top surface

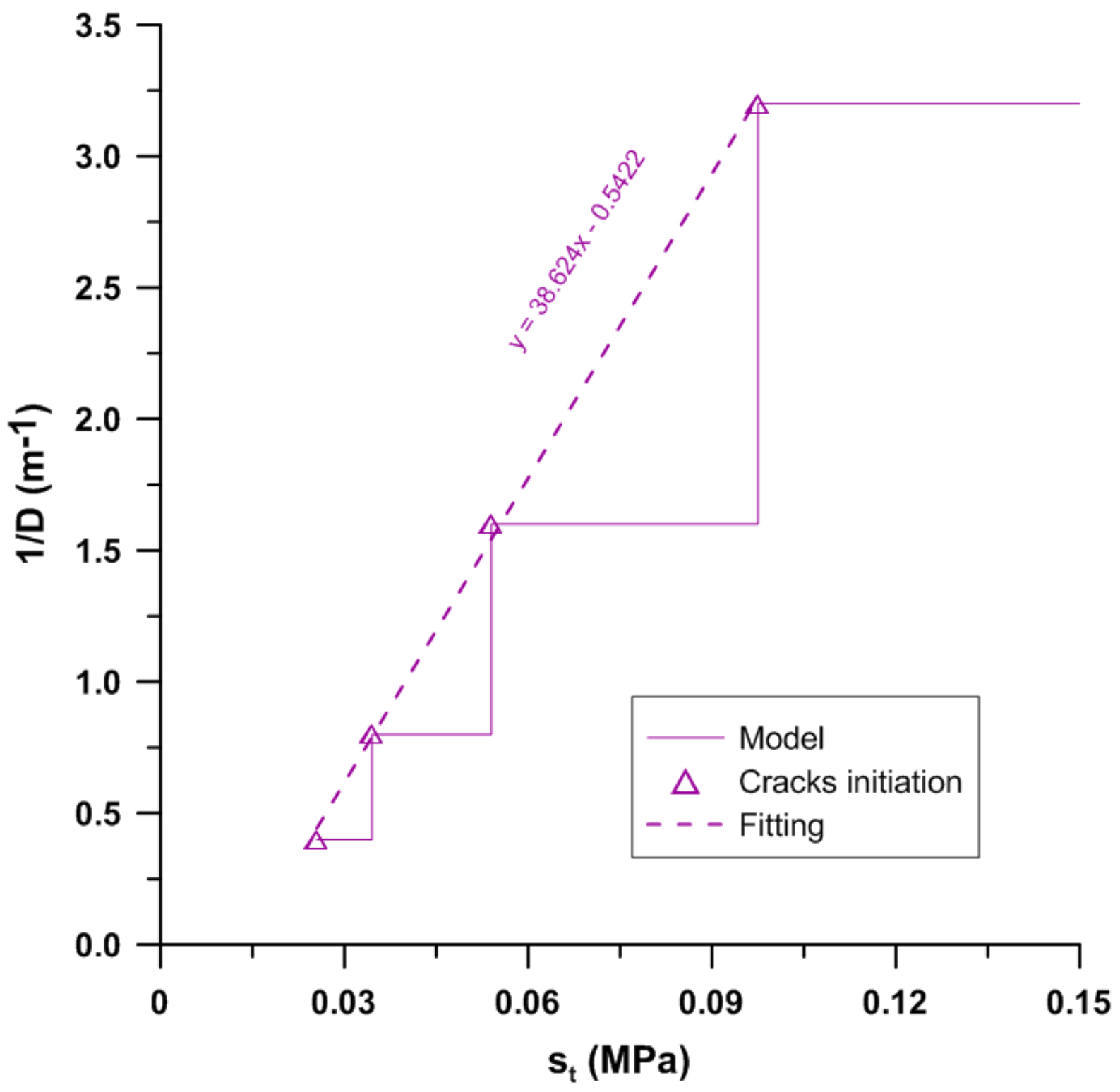


Figure 6: Ultimate depths for different cracks spacing: (a) versus the cracks spacing D and (b) versus $\mathrm{D}^{0.5}$ 


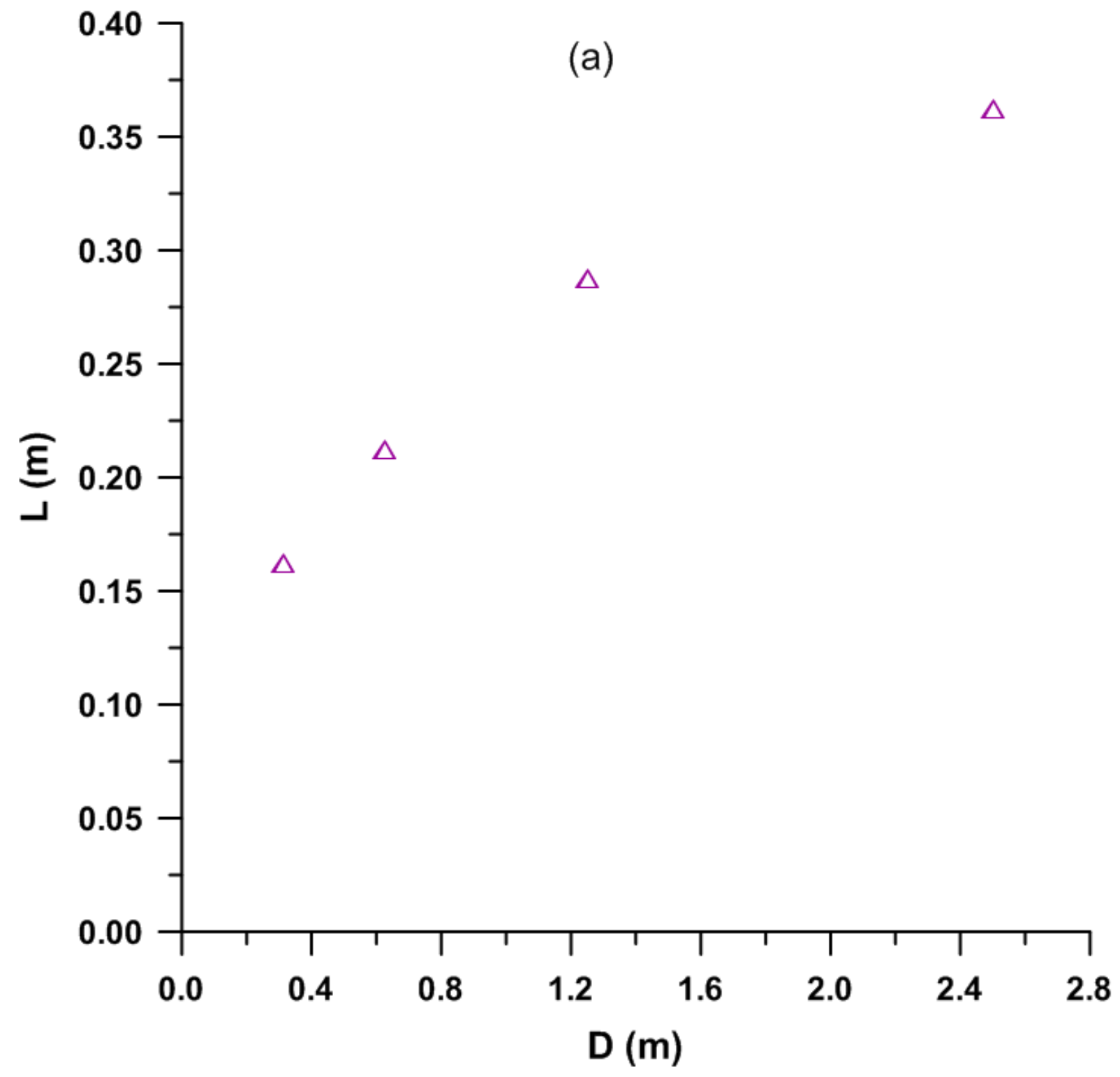




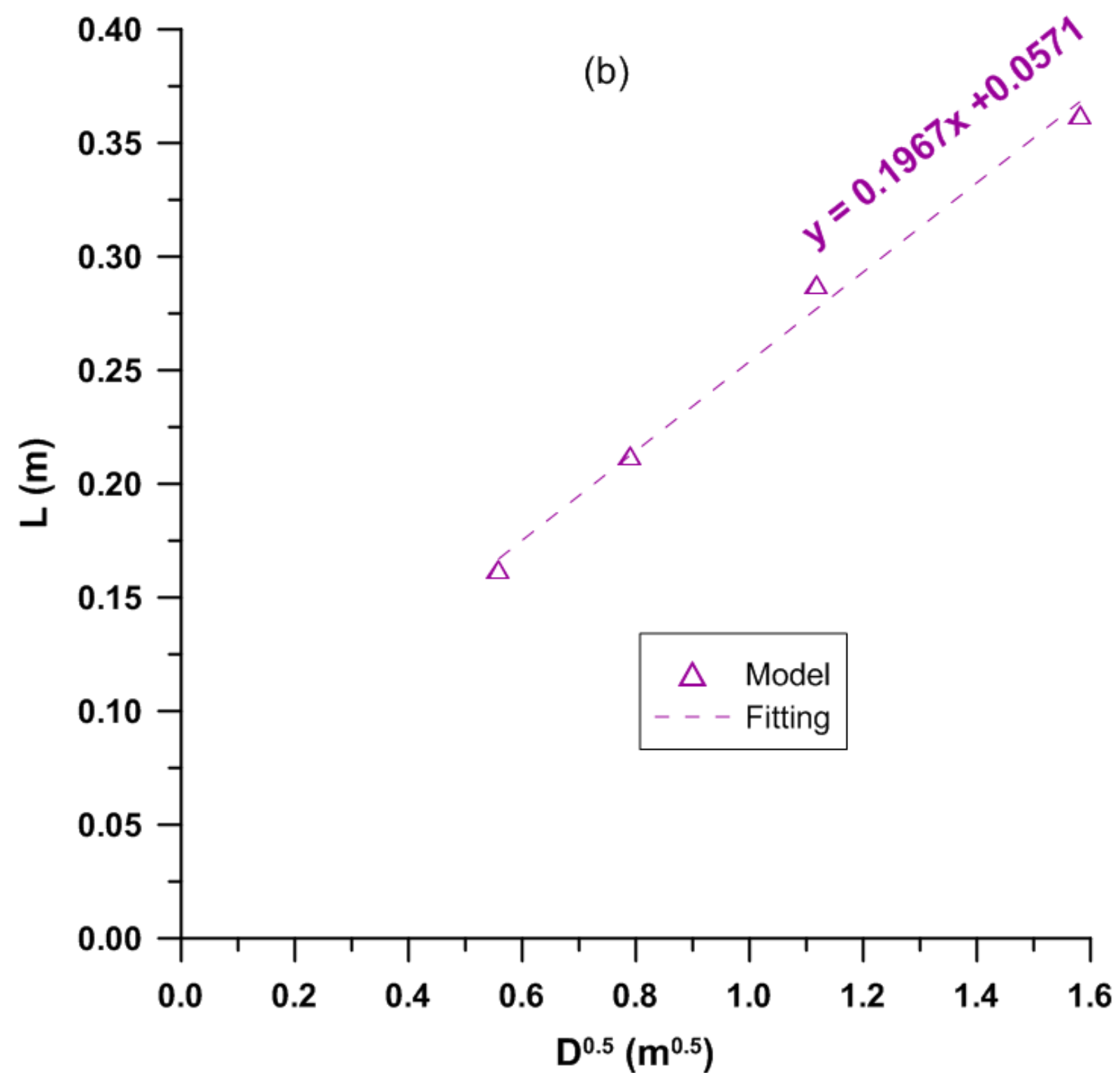


Figure 7: Tensile stress distribution on the top surface of the sample for various values of suction on the top surface

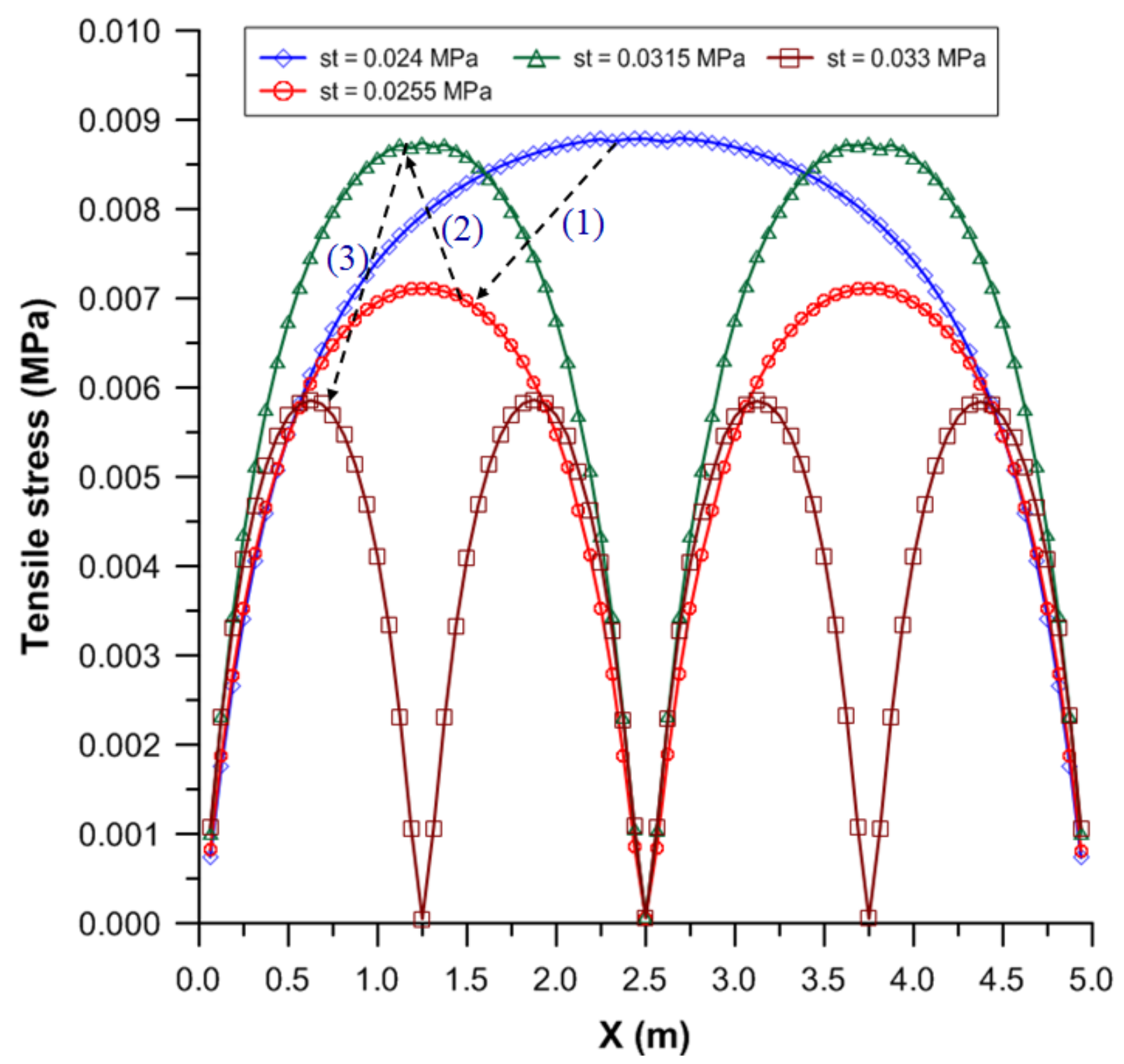


Figure 8: Cracks density versus suction on top surface for different values of $\gamma$

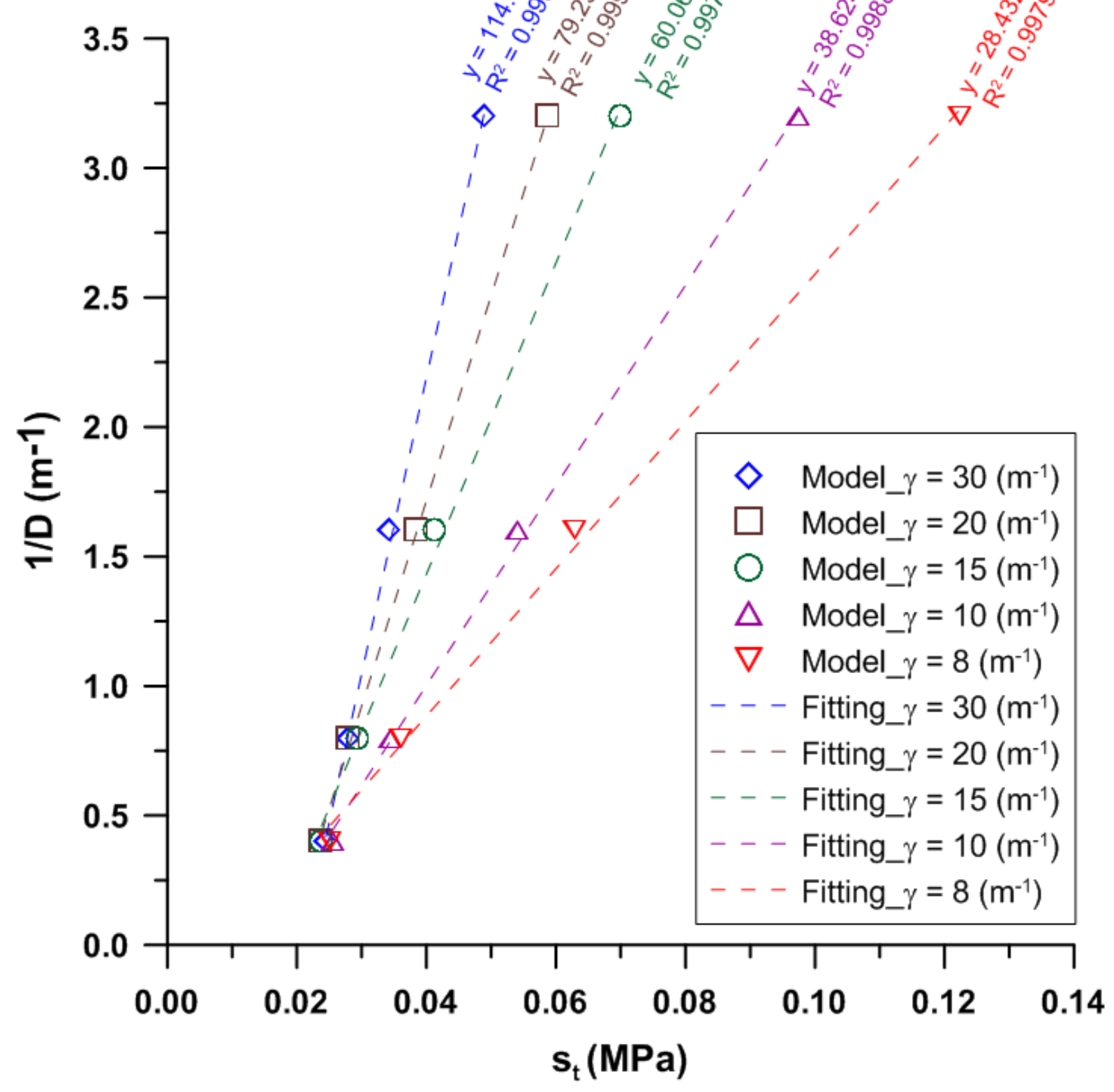


Figure 9: Ultimate crack depth versus the square root of cracks spacing for various values of $\gamma$

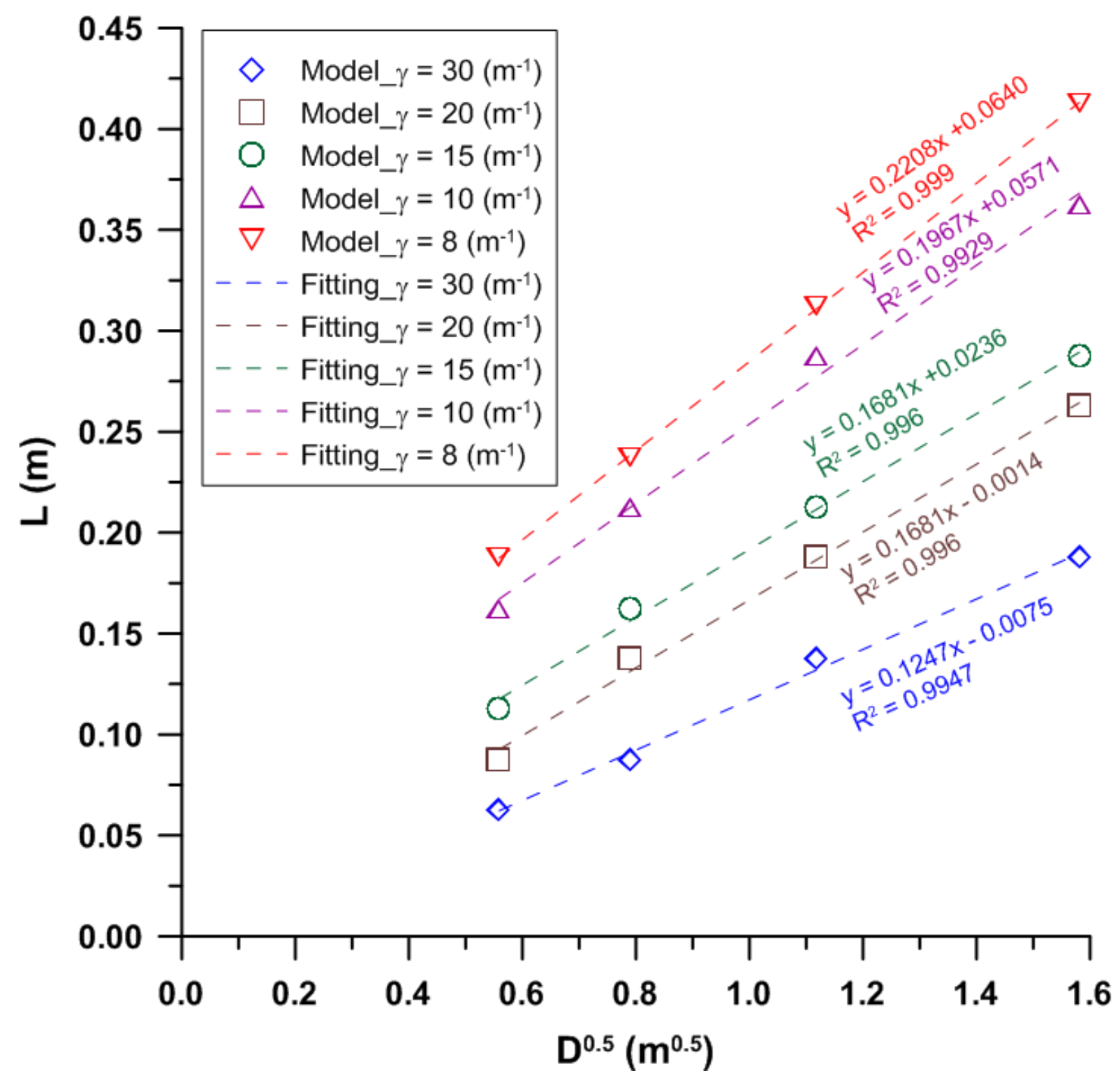


Figure 10: Cracks density versus suction on the top surface with different values of $\sigma_{R}$

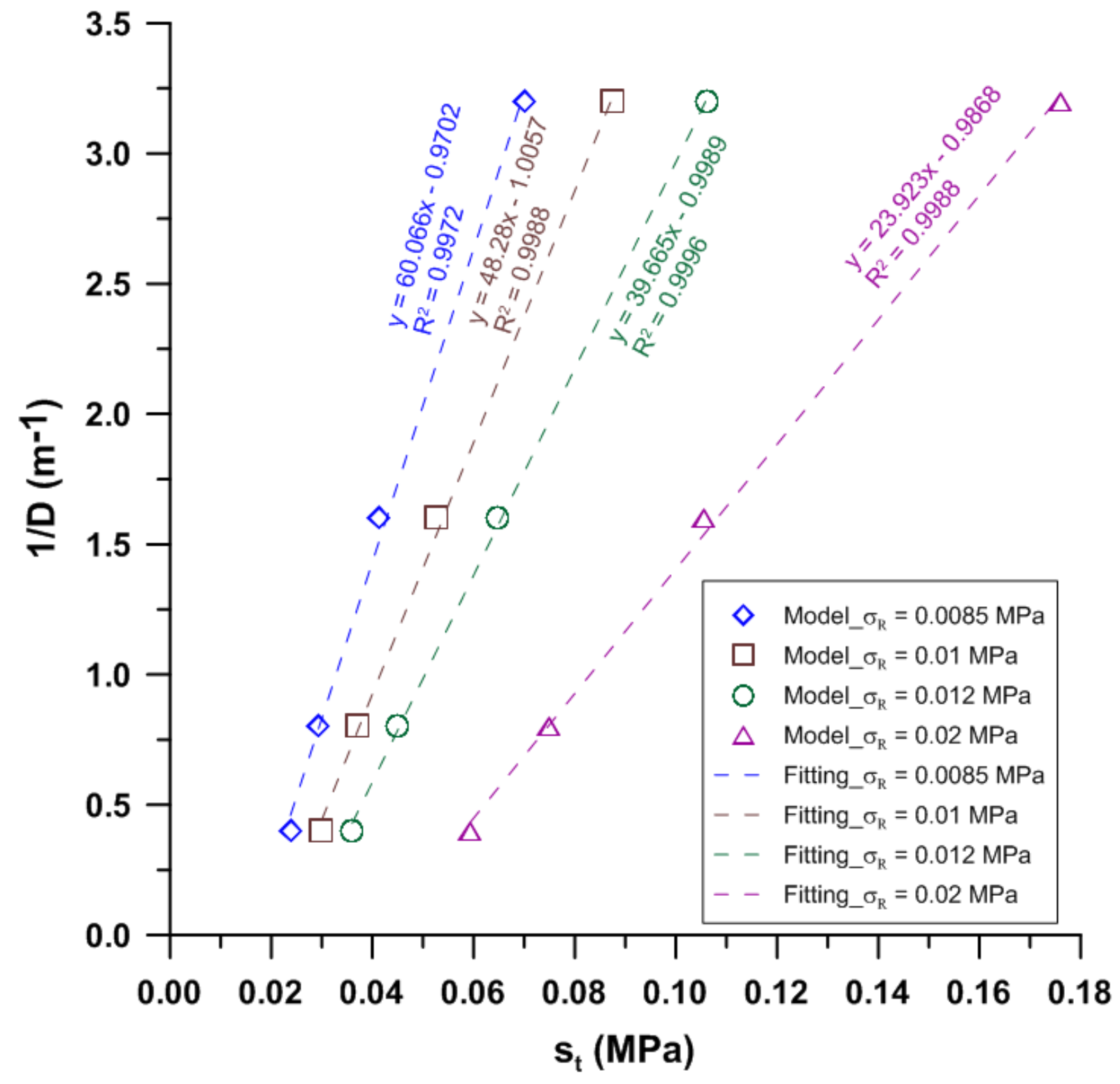


Figure 11: The suction s0 versus $\sigma_{\mathrm{R}}$

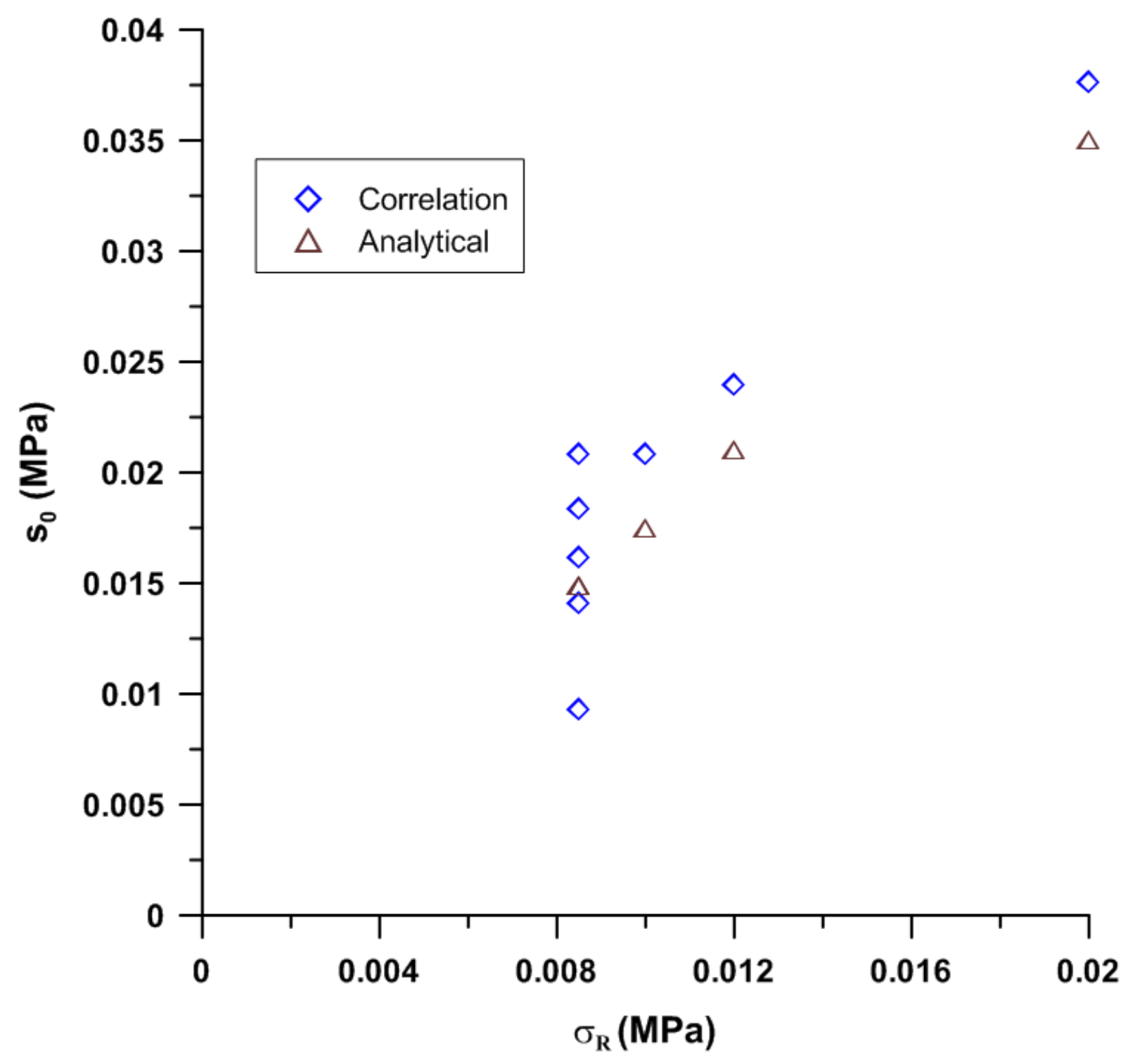


Figure 12: $\mathrm{k}(\gamma)$ versus $\gamma$

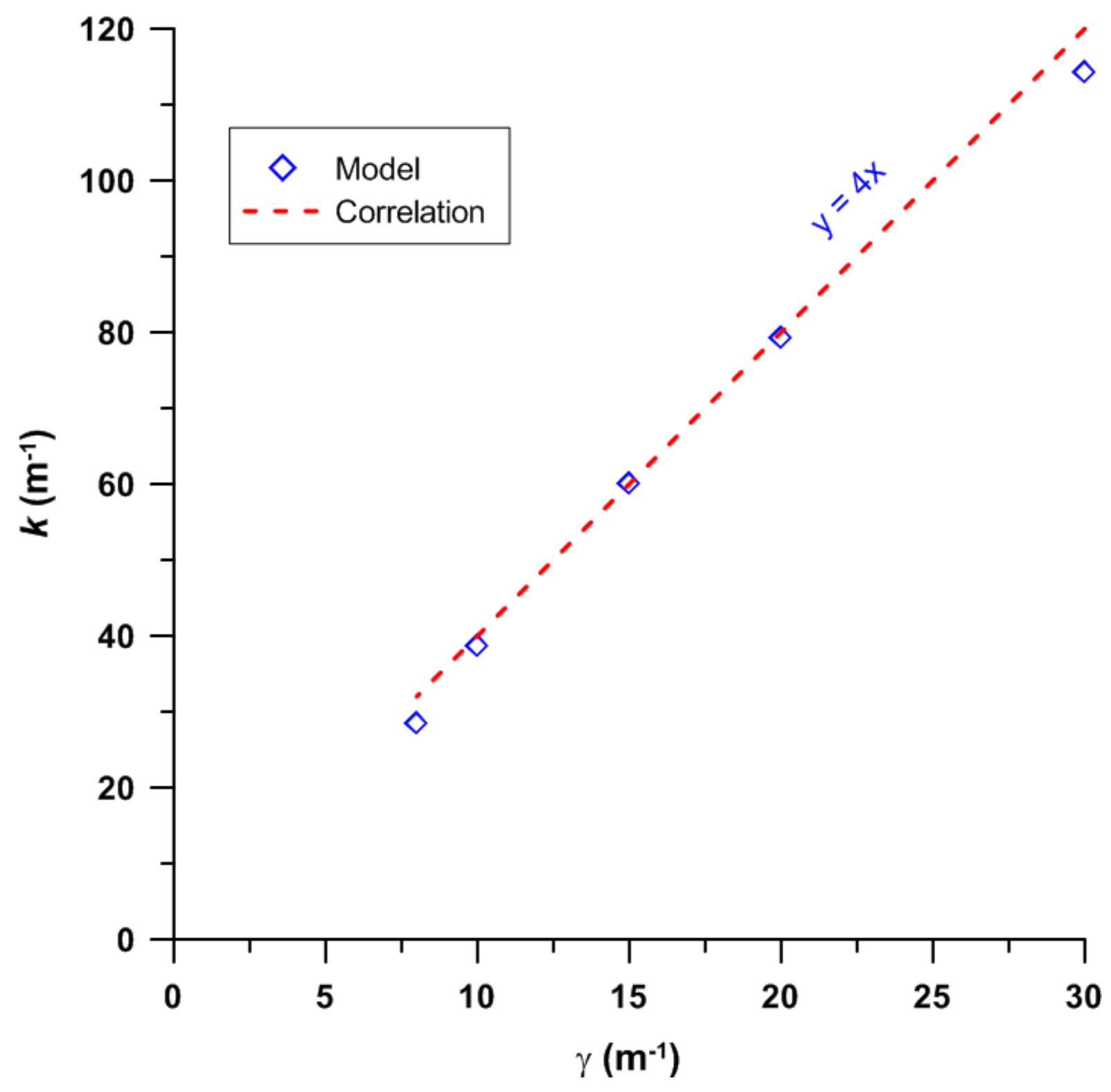


Figure 13: Approximation of $\mathrm{f}(\mathrm{y})$ function

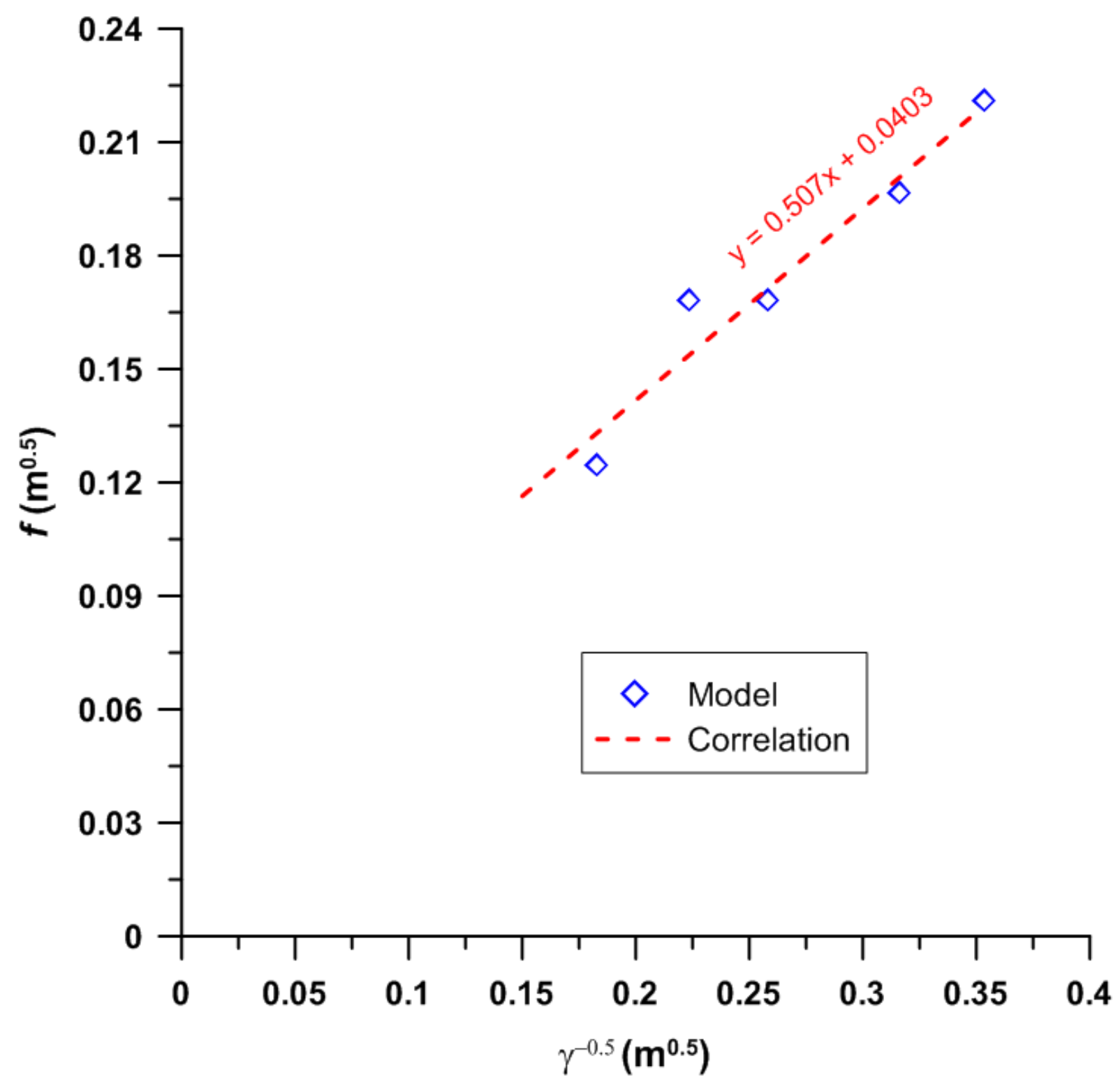


Figure 14: Suction profiles obtained by various methods

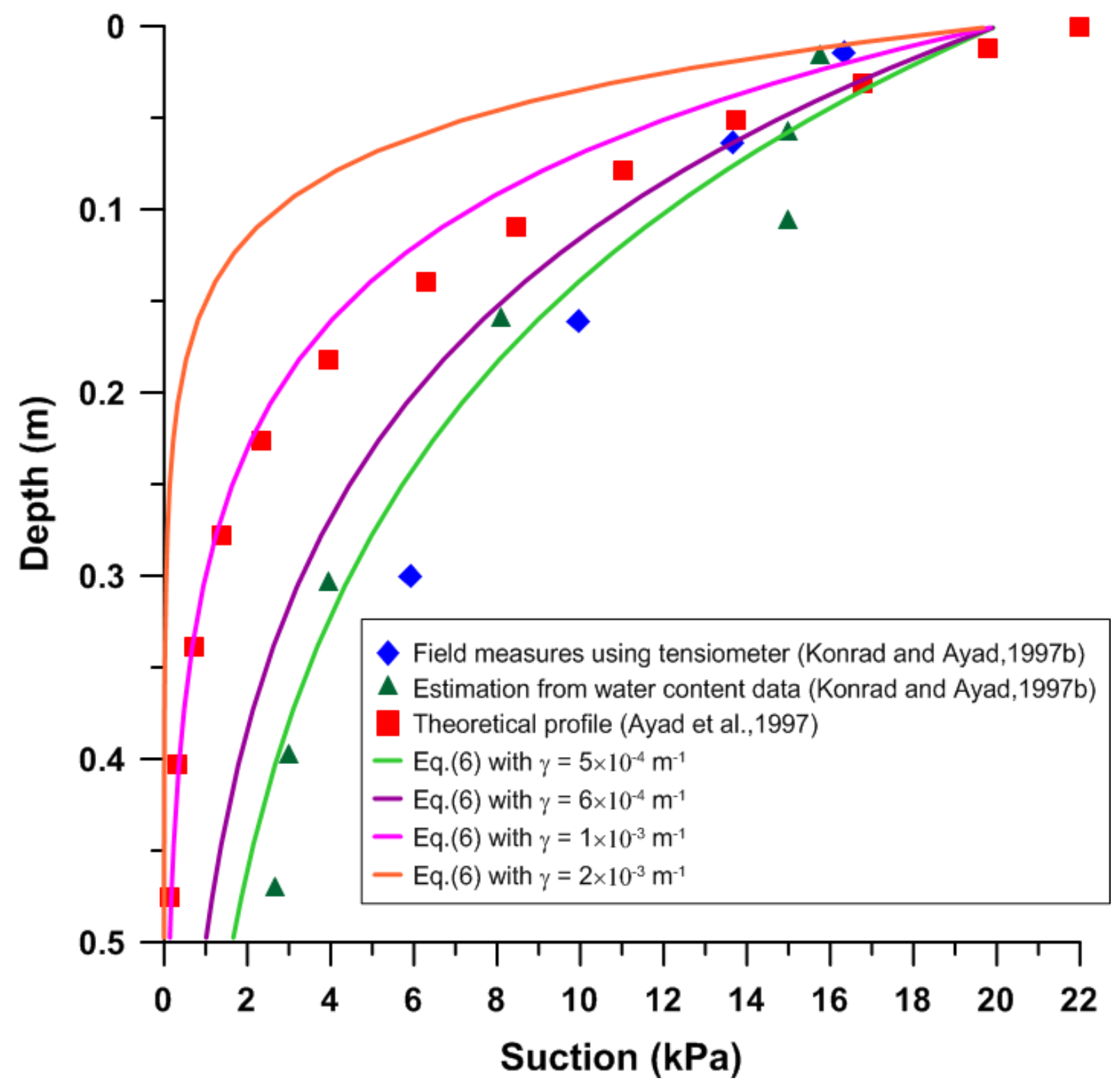


Table caption:

Table 1: Parameters of the reference case

\begin{tabular}{|l|l|}
\hline \multicolumn{2}{|l|}{} \\
\hline \multicolumn{2}{|l|}{} \\
\hline$E$ & \\
\hline$v$ & \\
\hline \multicolumn{2}{|l|}{} \\
\hline$R$ & \\
\hline$\sigma$ & \\
\hline$C$ & \\
\hline$\varphi$ & \\
\hline$\beta$ & \\
\hline & \\
\hline$\gamma$ & \\
\hline
\end{tabular}


